\title{
Cholesterol Crystal Embolism and Chronic Kidney Disease
}

\author{
Xuezhu Li ${ }^{1}$, George Bayliss ${ }^{2}$ and Shougang Zhuang ${ }^{1,2, *}$ \\ 1 Division of Nephrology, Tongji University School of Medicine, Shanghai 200120, China; xuezhuli@gmail.com \\ 2 Department of Medicine, Rhode Island Hospital and Alpert Medical School, Brown University, Providence, \\ RI 02903, USA; gbayliss@lifespan.org \\ * Correspondence: szhuang@lifespan.org; Tel.: +1-401-444-6847
}

Academic Editor: Alan Parrish

Received: 15 April 2017; Accepted: 20 May 2017; Published: 24 May 2017

\begin{abstract}
Renal disease caused by cholesterol crystal embolism (CCE) occurs when cholesterol crystals become lodged in small renal arteries after small pieces of atheromatous plaques break off from the aorta or renal arteries and shower the downstream vascular bed. CCE is a multisystemic disease but kidneys are particularly vulnerable to atheroembolic disease, which can cause an acute, subacute, or chronic decline in renal function. This life-threatening disease may be underdiagnosed and overlooked as a cause of chronic kidney disease (CKD) among patients with advanced atherosclerosis. CCE can result from vascular surgery, angiography, or administration of anticoagulants. Atheroembolic renal disease has various clinical features that resemble those found in other kidney disorders and systemic diseases. It is commonly misdiagnosed in clinic, but confirmed by characteristic renal biopsy findings. Therapeutic options are limited, and prognosis is considered to be poor. Expanding knowledge of atheroembolic renal disease due to CCE opens perspectives for recognition, diagnosis, and treatment of this cause of progressive renal insufficiency.
\end{abstract}

Keywords: cholesterol crystal embolism; atheroembolic renal disease; chronic kidney disease

\section{Introduction}

Cholesterol crystal embolism (CCE) occurs when small pieces of atheromatous plaques from the aorta or other major arteries break off and shower small arteries cholesterol crystal emboli. CCE is an important type of crystallopathy, as outlined in an elegant review from Mulay and Anders summarizing its pathophysiological mechanisms [1]. As a multisystemic disease, CCE involves many organs including kidneys, skin, gastrointestinal tract, eyes, muscle, central nervous system, and extremities. Embolic events usually are iatrogenic from surgical or invasive endovascular manipulation, but can also be spontaneous. Autopsy studies reported that kidneys were involved in $74 \%$ of cases of CCE. CCE is becoming a common cause of renal insufficiency in adults over the age of 60 with advanced atherosclerosis [2,3]. The clinical presentation of CCE is diverse, with limited therapeutic options and poor long-term outcomes for resulting atheroembolic renal disease [4]. This life-threatening disease may be underestimated and overlooked as a cause of chronic kidney disease (CKD) in patients with diffuse atherosclerosis and/or undergoing interventional cardiac catheterization, and its diagnosis and management still remain unresolved. In this review, we discuss the recent advances in the clinical and pathological findings in CCE.

\section{Etiology}

Atherosclerosis is a common disorder of arteries in which plaques composed of cholesterol, fatty substance, and other cellular waste on the intimal surface of arterial vessel walls form a plaque. 
The fibrous cap covering the plaques appears vulnerable to rupture, exposing the soft, cholesterol core of the plaque to the circulation. Then cholesterol crystals (CCs) move into the bloodstream and get stuck in arterioles (usually in medium-sized arteries 100 to $200 \mu \mathrm{m}$ in diameter) [4]. These CCs emboli lead to narrowing or obliteration of the arteriole lumen, resulting in ischemia and infarction of tissue distal to the cholesterol crystal emboli [5], potentially affecting the kidneys, skin, gastrointestinal system, eyes, muscles and bones, brain, nerves, visceral organs, and extremities [5]. The anatomical proximity of the kidneys to the abdominal aorta and degree of renal blood flow make the kidney a frequent target organ for cholesterol atheroembolism. Acute kidney failure is possible if acute arterial occlusion occurs when the artery that supplies blood to the kidney suddenly becomes blocked.

CCE is largely iatrogenic, often associated with aortic surgery, arterial invasive procedure with manipulation of the aorta or other major arteries, such as angiography, left heart catheterization, and coronary angioplasty. It is estimated that about 30-85\% of CCE patients have a history of invasive vascular procedure in the preceding 3 months, while only $4.3 \%$ had cholesterol embolism in age-matched controls that did not have invasive vascular procedure [6,7]. CCE is also a rare complication in patients undergoing the administration of anticoagulants (including heparin, low molecular weight heparin, warfarin, dabigatran) and thrombolytic therapy [2,7-10]. The incidence of CCE induced by these agents may increase rapidly with their widespread use for artrial fibrillation and acute myocardial infarction in recent years. One proposed explanation for anticoagulant and thrombolytic agents related CCE is that anticoagulants and thrombolytic treatment agents may initiate the rupture of plaques by causing internal hemorrhage or dissolution of fibrous caps, exposing the underlying low-density lipoprotein-derived CCs to the systemic circulation. Studies showed that anticoagulation agents could be implicated in 7\% of biopsy-proven CCE without arterial invasive procedures [2]. The incidence of CCE among patients taking warfarin is low $(0.7 \%$ to $1.0 \%)$ [2]. Patients with diffuse atherosclerosis may also suffer spontaneous detachment of plaques or continuous low-grade migration of CCs from the aortic wall. Spontaneous CCE is rare, with reported frequency ranging from $1.9 \%$ to $13 \%[2,11]$.

\section{Epidemiology}

The exact incidence of CCE is not known, as it is often underdiagnosed [2]. The reported incidence varies from $1.1 \%$ to $4.5 \%$ due to different study designs and diagnostic criteria [2,12]. Mayo and Swartz surveyed 402 consultation charts retrospectively, suggesting that the incidence of clinically detectable atheroembolism amounted to at least $4 \%$ of all inpatients examined [13]. Fukumoto and colleagues reported that $1.4 \%$ patients, among 1786 patients who underwent left-heart catheterization, were diagnosed with CCE, and that $64 \%$ of those patients had renal damage [14]. The incidence of CCE in autopsy studies is similar to that found in renal biopsy series [2,15]. CCE accounted for $7 \%$ of all causes of acute renal injury in a study of 259 patients, age 60 or older, who underwent renal biopsy [16].

CCE is becoming a common cause of renal failure in older adults with atherosclerosis [3]. Scolari et al. observed that $60 \%$ of 354 patients diagnosed with CCE were older than 70 years [7]. The other risk factors for $\mathrm{CCE}$ are the same as those for atherosclerosis, including male gender, Caucasian race, tobacco use, ischemic cardiovascular disease, cerebrovascular disease, hypertension, hypercholesterolemia, diabetes, hypercoagulability, abdominal aortic aneurysm, peripheral vascular disease, and family history [2-4,11].

\section{Pathogenesis}

The exact mechanism underlying CCE is not fully understood. The local tissue necrosis and inflammatory reaction caused by CCs play a significant role in the pathogenesis of CCE. Furthermore, activation of renin-angiotensin-aldosterone system, complement activation also contribute to the development of CCE. 


\subsection{Necroinflammation}

CCs cause tissue injury directly through mechanical obstruction that leads to vascular obstruction, tissue ischemia and cell necrosis, referred as "necroinflammation" [1]. Animal experiments showed that crystals lodged in a vessel lumen induce platelet aggregation, thrombosis and complete arterial obstruction [17]. The local inflammatory reaction caused by CCs may play a crucial role in the luminal occlusion and subsequent renal insufficiency. The CCs trigger a foreign-body inflammatory reaction around the arterioles, involving macrophage infiltration and foreign body giant cell reaction. A number of studies have described a series of reactions of the arterial wall to CCs. Jones and Iannacone divided the inflammation reaction into three phases [18]. In the early phase, fresh crystal emboli cause endothelial injury, including swelling of cells with dilated endoplasmic reticulum and osmotic damage in mitochondria [17]. Crystal emboli also cause an early histiocytic response, including transient appearance of neutrophils and eosinophils. The intermediate phase is characterized by a giant-cell infiltration and intimal proliferation. The late phase involves the encasement of the crystals by histiocytes, more intimal proliferation, and intravascular fibrosis [19].

CCs are emerging as an endogenous initiator of inflammation. Martinon, Tschopp, and colleagues found that crystals induce interleukin- $1 \beta$ activation in mononuclear phagocytes through the NLRP3 inflammasome [20]. The NLRP3 inflammasome is an intracellular platform that translates various danger signals into the activation of caspase- 1 and the secretion of interleukin- $1 \beta$. Duewell and colleagues [21] confirmed that CCs also activate the NLRP3 inflammasome to trigger the secretion of mature interleukin (IL)-1 $\beta$ and $\alpha$ from macrophages, leading to cell necrosis. In addition, Corr et al. report that CCs induce IL- $\alpha / \beta$ production through the activation of Syk and PI3K in human macrophages and dendritic cells [22]. Moreover, a recent study shows that CCs directly bind to the human macrophage-inducible C-type lectin (hMincle) and induce pro-inflammatory cytokine, such as tumor necrosis factor(TNF)and macrophage inflammatory protein 2(MIP-2), release [23].

\subsection{Activation of Renin-Angiotensin-Aldosterone System (RAAS)}

Blood pressure in patients with CCE is usually hard to control, with some evidence suggesting that CCE contributes to activation of RAAS. Tanaka et al. reported a case of severe hyperreninemic hypertension associated with spontaneous renal CCE [24]. Obstruction of arcuate arteries, interlobular arteries, afferent arterioles, or glomerular capillaries by CCs reduced focal blood perfusion and induced activation of RAAS, which exerts deleterious effects through oxidative stress leading to apoptosis, inflammation, and fibrosis [25]. In addition, RAAS also can promote vascular and tissue remodeling, further contributing to chronic kidney disease. Clinically, RAAS inhibitors may have a potential benefit for improvement of renal outcomes in CCE.

\subsection{Complement Activation}

Complement factors are involved in the inflammatory response associated with atherosclerosis. CCs activate both classical and alternative complement pathways [26,27]. In experiments with cultured endothelial cells, CCs activated complement factors, specifically C5a, leading to leukocyte aggregation and endothelial damage by release of leukocyte enzymes and oxidants [28]. A recent study demonstrated that CCs activated the classical complement pathway and TNF release, which caused endothelial activation in vitro [29]. Furthermore, CCs induced soluble terminal C5b-9 formation and C3c deposition on the CCs surface, increased the expression of complement receptor 3(CD11b/CD18) on monocytes and granulocytes in human whole blood, and reconstituted high density lipoprotein (rHDL) attenuated the complement activation induced by CCs [27]. Therefore, CC activation of complement is an important mechanism controlling the release of proinflammatory cytokines and inflammatory responses. 


\section{Pathology}

Renal complications of CCE are usually difficult to estimate clinically, owing to the syndrome's propensity to mimic other renal disorders. Kidney biopsy is considered the definitive test for diagnosis of CCE. On renal biopsy, the characteristic lesion of CCE is occlusion of cholesterol emboli in the lumina of arcuate, interlobular arteries, and glomeruli. The emboli of CCs generally are defined by the empty, biconvex, and needle-shaped clefts, appearing as "ghosts", because CCs usually dissolve during routine histologic preparation procedures. However, in frozen sections, the crystals are birefringent under polarized light and give positive histochemical reactions for lipids [30]. Interlobular and arcuate arteries showed a perivascular polymorphonuclear and eosinophilic infiltration. In the later stage of the disease, perivascular fibrosis occurs around the occluded vessels. Glomeruli can have normal morphology in the initial stage, but ischemic retraction of podocyte foot processes, focal segmental glomerulosclerosis (FSGS), interstitial fibrosis, and tubular atrophy can be seen frequently due to ongoing ischemic injury in the later stages of the disease (Figure 1). Generally, immunofluorescence staining for immunoglobulin A (IgA), IgG, IgM, C3, C1q, fibrin, kappa, and lambda light chains are negative [31]. Renal biopsy has a sensitivity of about $75 \%$. Involvement of renal vasculature is patchy, and the diagnosis may be missed if not enough sections are examined [32].

Renal biopsy is often not performed due to older age, comorbidity, and prior CKD, leading to a delay in diagnosis. Skin, muscle, or gastrointestinal (GI) biopsies may also provide evidence of cholesterol clefts in tissue and indirectly confirm the diagnosis without a renal biopsy. Skin biopsy is favored as an alternative to renal biopsy because it is less invasive, and skin lesions are involved in nearly $90 \%$ of CCE [30].

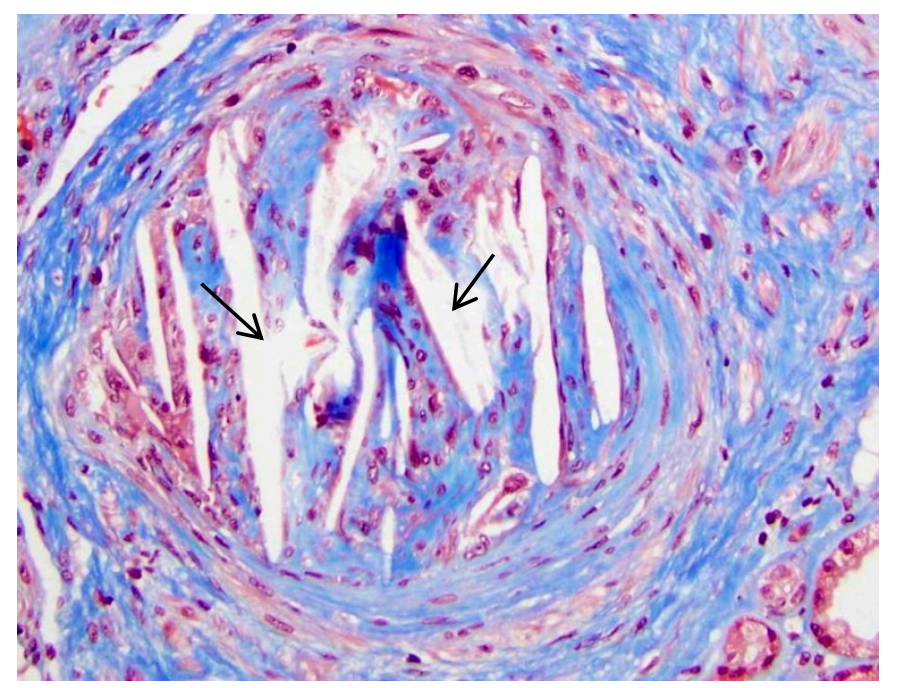

Figure 1. Pathological changes of cholesterol crystal embolism. Renal biopsy from a 68-year-old man with peripheral vascular disease, hypertension, abdominal aortic aneurysm shows the arcuate artery occluded by an organizing atheroembolus, consisting of cholesterol clefts (arrows), macrophages and lymphocytes, and fibroblasts. The patient had acute renal failure with serum creatinine $=11.8 \mathrm{mg} / \mathrm{dL}$. Masson Trichrome, Original Magnification 200×. Image courtesy of Isaac E. Stillman, M.D., Beth Israel Deaconess Medical Center/Harvard Medical School.

\section{Clinic Presentations}

\subsection{Renal Complication of Cholesterol Crystal Embolism (CCE)}

Renal complications of CCE, also known as atheroembolic renal disease (AERD), take two forms: acute/subacute and chronic (Table 1). The acute/subacute form presents as a sudden decline in renal function resulting from a massive shower of cholesterol crystal emboli due to abrupt rupture of unstable 
plaques. Acute CCE occurs within seven days after an inciting event with multiorgan CCE involvement. In the subacute presentation, renal insufficiency arises weeks or months after the inciting event. It can be explained by recurrent cholesterol crystal emboli showers and the foreign-body reaction.

Table 1. The clinical presentations of cholesterol crystal embolization.

\begin{tabular}{|c|c|}
\hline Organ & Clinical Presentations \\
\hline Kidney & $\begin{array}{l}\text { Acute or subacute kidney injury } \\
\text { Renal infarction } \\
\text { Chronic kidney disease } \\
\text { Renal allograft failure } \\
\text { Severe hard-to-control hypertension } \\
\text { Extra-renal organs }\end{array}$ \\
\hline Skin & $\begin{array}{l}\text { Livedo reticularis } \\
\text { Blue toe syndrome } \\
\text { Ulceration and gangrene } \\
\text { Purpura } \\
\text { Small nail bed infarcts } \\
\text { Leg, foot, or toe pain }\end{array}$ \\
\hline Gastrointestinal System & $\begin{array}{l}\text { Abdominal, flank, or back pain } \\
\text { Gastrointestinal bleeding } \\
\text { Diarrhea } \\
\text { Bowel ischemia, infarction, and obstruction } \\
\text { Pancreatitis, cholecystitis, and abnormal liver tests } \\
\text { Splenic infarcts }\end{array}$ \\
\hline Eyes & $\begin{array}{l}\text { Amaurosis fugax } \\
\text { Sudden blindness } \\
\text { Retinal plaques (Hollenhorst plaques) }\end{array}$ \\
\hline Central Nervous System & $\begin{array}{l}\text { Headache } \\
\text { Amaurosis fugax } \\
\text { Stroke } \\
\text { Transient ischaemic attacks } \\
\text { Altered mental status } \\
\text { Paraparesis } \\
\text { Mononeuropathy } \\
\text { Cerebral infarction } \\
\text { Spinal cord infarction }\end{array}$ \\
\hline Muscle & $\begin{array}{l}\text { Muscle pain } \\
\text { Arthralgias } \\
\text { Rhabdomyolysis } \\
\text { Systemic signs } \\
\text { Fever } \\
\text { Anorexia } \\
\text { Fatigue } \\
\text { Weight loss } \\
\text { Malaise } \\
\text { Myalgia }\end{array}$ \\
\hline
\end{tabular}

A chronic subset of CCE, presenting as a slowly progressive form, is likely due to frequent and slow crystal migration from ruptured atherosclerotic lesions [7,33-35]. It can be clinically silent when small non-significant cholesterol crystal embolism occurs in kidneys. Most published series emphasize the acute form of AERD. However, CCE is often overlooked because it mimics symptoms of several other chronic kidney diseases, such as chronic glomerular sclerosis, systemic vasculitis, ischemic nephropathy, hypertensive nephrosclerosis. Diagnosis of chronic CCE is difficult, often made postmortem. Interestingly, Greenberg and colleagues evaluated clinical presentations and pathological findings of 24 patients with CCE. Nine patients had nephrotic range proteinuria. Light microscopy 
and electron microscopy study disclosed focal segmental glomerulosclerosis (FSGS), largely of the cellular variant FSGS with podocyte hypertrophy and capillary loop collapse. It should be recognized that FSGS presenting with heavy proteinuria can occur as part of a chronic disorder, and CCE should be considered in the differential diagnosis of secondary FSGS [36].

There is no specific laboratory test for AERD [37]. Blood tests for elevation of serum creatinine can confirm the diagnosis of acute renal injury or chronic kidney disease but do not identify cause. Microscopic hematuria and minimal proteinuria is typically found on urinalysis. Nephrotic range proteinuria ( $>3 \mathrm{~g} /$ day) can be seen on occasion. Eosinophilia is common in CCE patients; the incidence varies from $14 \%$ to $71 \%$. Eosinophilia is usually transient, due to release of interleukin- 5 by activated $\mathrm{T}$ cells [32]. Urinary eosinophilia has also been reported in cases [38]. Elevated erythrocyte sedimentation rate, C-reactive protein levels, and transient $\mathrm{C} 3$ hypocomplementemia may be present, but not specific.

Renal pathology can also include membranous nephropathy [36] and purpura nephritis [39]. CCE was associated with renal dysfunction caused by CC-induced ischemic interstitial damage (tubular atrophy and fibrosis) in those scenarios. CCE may also occur even in end-stage renal disease patients who are undergoing maintenance dialysis $[4,40,41]$.

Cholesterol embolism can also occur in transplanted kidney. CCE in renal allografts is a rare condition with a reported incidence of about $0.39 \%$ to $0.47 \%$ [42]. Common clinical manifestation, risk factors, and potential triggers are the same as cholesterol crystal embolism in native kidneys. Atheroemboli may arise from either donor or recipient vessels. Embolization of donor origin occurred early after transplantation, causing primary renal allograft failure, while cholesterol embolization from recipient causes a late chronic allograft dysfunction, which usually occurs years after transplantation in a stable graft $[43,44]$. CCE is an important and under-reported cause of renal allograft dysfunction and should be considered when either primary or late renal graft failure occurs [45].

\subsection{Extra-Renal Manifestation}

The syndrome of CCE has various clinical features (Table 1). The most common extra-renal manifestation of CCE is in skin, with reported frequency of $75 \%$ to $96 \%$. Skin manifestations, usually limited to the lower extremities, are most commonly livedo reticularis (purplish rash) and blue toe syndrome, ulceration, gangrene, purpura, small nail bed infarcts, leg, foot, or toe pain $[41,46,47]$. Skin findings frequently occur on the trunk and rarely on the upper extremities, but we diagnosed one case of painful livedo reticularis on the sole of the right foot (Figure 2).

Other organs, including gastrointestinal tract, retina, central nervous system, skeletal muscle, pancreas, liver, spinal cord, prostate, adrenal glands, and heart may also be affected [2]. The distribution of end-organ damage depends on the anatomic location of the original atherosclerotic emboli and the extent of organ involvement. Visceral ischemia presents as abdominal pain and flank or back pain, gastrointestinal bleeding, infarction and obstruction (caused by gastrointestinal ischemia), diarrhea, cholecystitis, and splenic infarcts. Pancreatic ischemia leads to acute pancreatitis with elevated pancreatic enzymes. The retina is also a frequent target organ of atheroembolism, with the incidence varying from $11 \%$ to $25 \%$ [48]. Emboli in retinal arterioles can cause sudden blindness, amaurosis fugax, and be seen on fundoscopy as bright yellow retinal plaques (Hollenhorst plaques). Neurological features include headache, amaurosis fugax, stroke, altered mental status, paraparesis, mononeuropathy, cerebral and spinal cord infarction [49]. The musculoskeletal features include muscle pain, arthralgias, and rhabdomyolysis.

Constitutional signs and symptoms may include fever, anorexia, fatigue, weight loss, malaise, and myalgias. These may be only non-specific inflammatory responses with increased erythrocyte sedimentation rate and eosinophilia. Hypocomplementemia can also be observed in AERD, because the CCs from atheromatous plaques can activate the complement pathway [50]. 


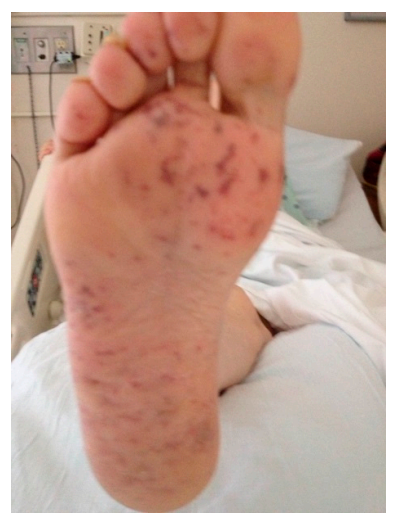

Figure 2. Photograph of painful livedo reticularis. Painful livedo reticularis on the sole of the right foot of a 57-year-old woman with diabetes, coronary artery disease, hyperlipidemia, stage V chronic kidney disease who underwent right carotid artery stenting for amaurosis fugax. The procedure was done by interventional radiology through a right femoral artery approach. The patient was placed on clopidogrel after stenting. Serum creatinine was $4.86 \mathrm{mg} / \mathrm{dL}$ on admission for the carotid artery stenting but dropped to baseline $3.74 \mathrm{mg} / \mathrm{dL}$ after the procedure. She presented a week later complaining of foot pain and was found to have tender petechial spots on the sole of her right foot. Creatinine was now $4.66 \mathrm{mg} / \mathrm{dL}$, but with supportive care came back to baseline at $3.64 \mathrm{mg} / \mathrm{dL}$ on discharge. The picture is used with the patient's permission.

\section{Treatments}

There is no specific therapy for AERD. Withdrawal of any form of anticoagulants, postponing aortic catheterization and surgery should be considered firstly to avoid CCE recurrence. The aim of treatment is to prevent the progression of tissue ischemia and further showering of cholesterol crystals or provide supportive care in the event of renal failure.

\subsection{Corticosteroids}

The aim of corticosteroid use is to reduce the reactive inflammatory response along with atheroembolization, but the effects of steroids remain controversial. Some studies demonstrated that oral prednisolone administered at a dose of $1 \mathrm{mg} / \mathrm{kg} /$ day led to overall clinical improvement and improved renal outcomes in CCE patients [51]. Fabbian et al. reported a case of CCE treated successfully with high-dose methylprednisolone (250 mg intravenously) followed by oral administration of prednisone $50 \mathrm{mg}$ a day gradually tapered off over 6 months. [52]. A small case series of renal CCE patients [53] and individual case reports also demonstrated that corticosteroid treatment led to improvement in renal function and other clinical symptoms [47,51]. However, other studies showed that corticosteroids did not have a favorable effect on long-term renal outcomes and were even associated with an increased risk of mortality [54-56].

\subsection{Lipid-Lowering Therapies}

Statins may have a beneficial effect in AERD by contributing to plaque stabilization and regression through their lipid-lowering and anti-inflammatory properties [48,57]. Unfortunately, there has been no randomized trial of statin therapy in patients with severe aortic plaque [56]. A recent study reported that low-density lipoprotein apheresis (LDL-A) decreased the risk of maintenance dialysis in 49 CCE patients with renal dysfunction after 24 weeks [58]. Lipoprotein apheresis (LA) can significantly lower lipoprotein cholesterol levels, and is recommended in some countries in very high-risk patients with early or progressive cardiovascular disease (CVD) [59]. LDL-A may have beneficial effect on renal outcome of CCE. 


\subsection{Dialysis and Other Therapies}

Patients with acute kidney injury may require dialysis therapy. Both peritoneal dialysis and hemodialysis have been shown to be adequate means of managing renal failure in such patients. Belenfant et al. recommend heparin-free dialysis to avoid anticoagulation and thereby prevent further embolization [60]. Surgical measures, such as endarterectomy, vessel ligation or bypass, may decrease the probability of further embolism [61]. There is no evidence that anti-inflammatory treatments and antiplatelet agents are beneficial.

\section{Outcome}

Cholesterol crystal microemboli are commonly associated with irreversible organ damage and a generally poor prognosis. Renal outcomes are variable, with some patients requiring maintenance dialysis and others showing improvement in renal function but with varying degrees of residual chronic kidney disease. About 30-55\% of acute/subacute CCE patients need dialysis [7,62]. Renal function recovery has been reported in only $21-28 \%$ of such cases [62]. Another $23-32 \%$ of AERD patients progress to end-stage renal disease (ESRD) [48]. Preexisting chronic kidney disease is associated with increased risk of progressing to ESRD in AERD [48,62]. A prospective study of 25 patients using endovascular stent graft coverage of embolizing aortic lesions showed that $12 \%$ had stage IV chronic kidney disease, and two of them became dialysis-dependent. Although the patients had chronic renal insufficiency and received a contrast load with computerized tomography (CT) imaging, their kidney function did not worsen after endovascular treatment [63]. One and two-year patient survival rates of $87 \%$ and $75 \%$, respectively, have been reported while the 4 -year survival rate drops to $52 \%$ [60]. Mortality is high, varying from $64 \%$ to $81 \%$ [64-66]. The major cause of death is cardiovascular disease [67]. Age, diabetes, history of heart failure, baseline renal function, time course of decline in renal function, and extra-renal manifestations are risk factors for both ESRD and death [7].

\section{Prevention}

Prevention is important for AERD in large part because no effective treatment is available at present. Prophylaxis against further episodes of cholesterol embolization is beneficial. CCE is a serious complication of invasive vascular procedures, with the incidence of CCE ranging from $1.4 \%$ to $2.0 \%[14,68]$. Some experts recommend limiting excess anticoagulation and restricting angiography and surgical procedures as much as possible in patients with severe atherosclerosis $[60,69]$. New noninvasive diagnostic tools, such as spiral computed tomographic angiography, angiomagnetic resonance, and duplex ultrasonography, might reduce catheter-induced CCE. Technical considerations such as minimizing contrast angiography during invasive procedures, use of intravascular ultrasound or transesophageal echocardiography, and minimizing wire/catheter manipulation and balloon angioplasty all play important roles in minimizing kidney injury and morbidity related to further embolic phenomena $[63,70]$.

\section{Conclusions}

The expansion of intravascular catheterization to treat a wide variety of atherosclerotic diseases has greatly reduced mortality from cardiovascular diseases in the last decade but has also increased the incidence of $\mathrm{CCE}$, a complex phenomenon with its own significant morbidity and mortality. However, diagnosis of CCE remains a clinical challenge since its symptoms are non-specific symptoms. Understanding the risk factors for and causes of CCE should help physicians diagnose the syndrome in patients with a history of atherosclerosis and an invasive arterial procedure who present with acute/subacute or chronic renal failure. Awareness of those risk factors and causes may also help physicians reduce damage from intravascular intervention by considering non-invasive alternatives or preparing for it when an invasive intravascular procedure cannot be avoided. 
Acknowledgments: This work was supported by the National Nature Science Foundation of China (81500511 to Xuezhu Li; 81470920 and 81670623 to Shougang Zhuang); Shanghai Pujiang Talent Foundation of China (15PJ1407100), and US National Institutes of Health (2R01DK08506505A1 to Shougang Zhuang).

Author Contributions: Xuezhu Li designed and wrote the manuscript; George Bayliss and Shougang Zhuang edited the manuscript.

Conflicts of Interest: The authors declare no conflict of interest.

\section{References}

1. Mulay, S.R.; Anders, H.J. Crystallopathies. N. Engl. J. Med. 2016, 374, 2465-2476. [CrossRef] [PubMed]

2. Scolari, F.; Ravani, P. Atheroembolic renal disease. Lancet 2010, 375, 1650-1660. [CrossRef]

3. Chronopoulos, A.; Rosner, M.H.; Cruz, D.N.; Ronco, C. Acute kidney injury in the elderly: A review. Contrib. Nephrol. 2010, 165, 315-321. [PubMed]

4. Venturelli, C.; Jeannin, G.; Sottini, L.; Dallera, N.; Scolari, F. Cholesterol crystal embolism (atheroembolism). Heart Int. 2006, 2, 155. [CrossRef] [PubMed]

5. Saric, M.; Kronzon, I. Cholesterol embolization syndrome. Curr. Opin. Cardiol. 2011, 26, 472-479. [CrossRef] [PubMed]

6. Van Rosendael, P.J.; Kamperidis, V.; van der Kley, F.; Katsanos, S.; Al Amri, I.; Regeer, M.V.; Schalij, M.J.; de Weger, A.; Marsan, N.A.; Bax, J.J.; et al. Atherosclerosis burden of the aortic valve and aorta and risk of acute kidney injury after transcatheter aortic valve implantation. J. Cardiovasc. Comput. Tomogr. 2015, 9, 129-138. [CrossRef] [PubMed]

7. Scolari, F.; Ravani, P.; Gaggi, R.; Santostefano, M.; Rollino, C.; Stabellini, N.; Colla, L.; Viola, B.F.; Maiorca, P.; Venturelli, C.; et al. The challenge of diagnosing atheroembolic renal disease: Clinical features and prognostic factors. Circulation 2007, 116, 298-304. [CrossRef] [PubMed]

8. Shafi, S.T.; Negrete, H.; Roy, P.; Julius, C.J.; Sarac, E. A case of dabigatran-associated acute renal failure. WMJ 2013, 112, 173-175. [PubMed]

9. Carron, P.L.; Florea, A.; Ducloux, D.; Jamali, M.; Chalopin, J.M. Atheroembolic disease associated with the use of low-molecular-weight heparin during haemodialysis. Nephrol. Dial. Transplant. 1999, 14, 520-521. [CrossRef] [PubMed]

10. Cortez, A.F.; Sakuma, T.H.; Lima, R.B.; de Figueiredo, W.M.; Valle Hde, A.; Tolstoy, F.A.; Coimbra, D.D.; Lupi, O. Cholesterol crystal embolization caused by anticoagulant therapy. Int. J. Dermatol. 2009, 48, 989-990. [CrossRef] [PubMed]

11. Turina, S.; Mazzola, G.; Venturelli, C.; Valerio, F.; Dallera, N.; Kenou, R.; Sottini, L.; Maffeo, D.; Tardanico, R.; Faggiano, P.; et al. Atheroembolic renal disease. G. Ital. Nefrol. 2009, 26, 181-190. [PubMed]

12. Mittal, B.V.; Alexander, M.P.; Rennke, H.G.; Singh, A.K. Atheroembolic renal disease: A silent masquerader. Kidney Int. 2008, 73, 126-130. [CrossRef] [PubMed]

13. Mayo, R.R.; Swartz, R.D. Redefining the incidence of clinically detectable atheroembolism. Am. J. Med. 1996, 100, 524-529. [CrossRef]

14. Fukumoto, Y.; Tsutsui, H.; Tsuchihashi, M.; Masumoto, A.; Takeshita, A.; Cholesterol Embolism Study(CHEST) Investigators. The incidence and risk factors of cholesterol embolization syndrome, a complication of cardiac catheterization: A prospective study. J. Am. Coll. Cardiol. 2003, 42, 211-216. [CrossRef]

15. Moolenaar, W.; Lamers, C.B. Cholesterol crystal embolization in the Netherlands. Arch. Intern. Med. 1996, 156, 653-657. [CrossRef] [PubMed]

16. Haas, M.; Spargo, B.H.; Wit, E.J.; Meehan, S.M. Etiologies and outcome of acute renal insufficiency in older adults: A renal biopsy study of 259 cases. Am. J. Kidney Dis. 2000, 35, 433-447. [CrossRef]

17. Warren, B.A.; Vales, O. The ultrastructure of the stages of atheroembolic occlusion of renal arteries. Br. J. Exp. Pathol. 1973, 54, 469-478. [PubMed]

18. Jones, D.B.; Iannaccone, P.M. Atheromatous emboli in renal biopsies. An ultrastructural study. Am. J. Pathol. 1975, 78, 261-276. [PubMed]

19. Bradamante, M. Cholesterol crystal embolization. Acta Dermatovenerol. Croat 2007, 15, 114-115. [PubMed]

20. Martinon, F.; Petrilli, V.; Mayor, A.; Tardivel, A.; Tschopp, J. Gout-associated uric acid crystals activate the NALP3 inflammasome. Nature 2006, 440, 237-241. [CrossRef] [PubMed] 
21. Duewell, P.; Kono, H.; Rayner, K.J.; Sirois, C.M.; Vladimer, G.; Bauernfeind, F.G.; Abela, G.S.; Franchi, L.; Nunez, G.; Schnurr, M.; et al. NLRP3 inflammasomes are required for atherogenesis and activated by cholesterol crystals. Nature 2010, 464, 1357-1361. [CrossRef] [PubMed]

22. Corr, E.M.; Cunningham, C.C.; Dunne, A. Cholesterol crystals activate Syk and PI3 kinase in human macrophages and dendritic cells. Atherosclerosis 2016, 251, 197-205. [CrossRef] [PubMed]

23. Kiyotake, R.; Oh-Hora, M.; Ishikawa, E.; Miyamoto, T.; Ishibashi, T.; Yamasaki, S. Human Mincle Binds to Cholesterol Crystals and Triggers Innate Immune Responses. J. Biol. Chem. 2015, 290, 25322-25332. [CrossRef] [PubMed]

24. Tanaka, M.; Matsuo, K.; Shoda, H.; Takami, S.; Naruse, M.; Matsuyama, K. Severe hyperreninemic hypertension associated with spontaneous renal cholesterol crystal embolization. Clin. Exp. Nephrol. 2004, 8, 150-154. [CrossRef] [PubMed]

25. Calo, L.A.; Schiavo, S.; Davis, P.A.; Pagnin, E.; Mormino, P.; D’Angelo, A.; Pessina, A.C. Angiotensin II signaling via type 2 receptors in a human model of vascular hyporeactivity: Implications for hypertension. J. Hypertens. 2010, 28, 111-118. [CrossRef] [PubMed]

26. Samstad, E.O.; Niyonzima, N.; Nymo, S.; Aune, M.H.; Ryan, L.; Bakke, S.S.; Lappegard, K.T.; Brekke, O.L.; Lambris, J.D.; Damas, J.K.; et al. Cholesterol crystals induce complement-dependent inflammasome activation and cytokine release. J. Immunol. 2014, 192, 2837-2845. [CrossRef] [PubMed]

27. Niyonzima, N.; Samstad, E.O.; Aune, M.H.; Ryan, L.; Bakke, S.S.; Rokstad, A.M.; Wright, S.D.; Damas, J.K.; Mollnes, T.E.; Latz, E.; et al. Reconstituted High-Density Lipoprotein Attenuates Cholesterol Crystal-Induced Inflammatory Responses by Reducing Complement Activation. J. Immunol. 2015, 195, 257-264. [CrossRef] [PubMed]

28. Hammerschmidt, D.E.; Greenberg, C.S.; Yamada, O.; Craddock, P.R.; Jacob, H.S. Cholesterol and atheroma lipids activate complement and stimulate granulocytes. A possible mechanism for amplification of ischemic injury in atherosclerotic states. J. Lab. Clin. Med. 1981, 98, 68-77. [PubMed]

29. Nymo, S.; Niyonzima, N.; Espevik, T.; Mollnes, T.E. Cholesterol crystal-induced endothelial cell activation is complement-dependent and mediated by TNF. Immunobiology 2014, 219, 786-792. [CrossRef] [PubMed]

30. Lye, W.C.; Cheah, J.S.; Sinniah, R. Renal cholesterol embolic disease. Case report and review of the literature. Am. J. Nephrol. 1993, 13, 489-493. [CrossRef] [PubMed]

31. Dummer, C.D.; Veronese, F.J.; Piana, M. Atheroembolic renal disease: A cause of acute renal failure not much explored. Rev. Assoc. Med. Bras. 2010, 56, 510-513. [CrossRef] [PubMed]

32. Modi, K.S.; Rao, V.K. Atheroembolic renal disease. J. Am. Soc. Nephrol. 2001, 12, 1781-1787. [PubMed]

33. Scolari, F.; Tardanico, R.; Zani, R.; Pola, A.; Viola, B.F.; Movilli, E.; Maiorca, R. Cholesterol crystal embolism: A recognizable cause of renal disease. Am. J. Kidney Dis. 2000, 36, 1089-1109. [CrossRef] [PubMed]

34. Polu, K.R.; Wolf, M. Clinical problem-solving. Needle in a haystack. N. Engl. J. Med. 2006, 354, 68-73. [CrossRef] [PubMed]

35. Meyrier, A. Cholesterol crystal embolism: Diagnosis and treatment. Kidney Int. 2006, 69, $1308-1312$. [CrossRef] [PubMed]

36. Greenberg, A.; Bastacky, S.I.; Iqbal, A.; Borochovitz, D.; Johnson, J.P. Focal segmental glomerulosclerosis associated with nephrotic syndrome in cholesterol atheroembolism: Clinicopathological correlations. Am. J. Kidney Dis. 1997, 29, 334-344. [CrossRef]

37. Quinones, A.; Saric, M. The cholesterol emboli syndrome in atherosclerosis. Curr. Atheroscler. Rep. 2013, 15, 315. [CrossRef] [PubMed]

38. Wilson, D.M.; Salazer, T.L.; Farkouh, M.E. Eosinophiluria in atheroembolic renal disease. Am. J. Med. 1991, 91, 186-189. [CrossRef]

39. Sakan, H.; Nakatani, K.; Asai, O.; Matsui, M.; Iwano, M.; Saito, Y. Case of purpura nephritis accompanied by idiopathic cholesterol embolism. Nihon Jinzo Gakkai Shi 2012, 54, 622-628. [PubMed]

40. Chu, J.K.; Folkert, V.W. Renal function recovery in chronic dialysis patients. Semin. Dial. 2010, $23,606-613$. [CrossRef] [PubMed]

41. Piccoli, G.B.; Quaglia, M.; Quaglino, P.; Burdese, M.; Bermond, F.; Mezza, E.; Jeantet, A.; Segoloni, G.P. Acute digital gangrene in a long-term dialysis patient-A diagnostic challenge. Med. Sci. Monit. 2002, 8, CS83-CS89. [PubMed]

42. Lai, C.K.; Randhawa, P.S. Cholesterol embolization in renal allografts: A clinicopathologic study of 12 cases. Am. J. Surg. Pathol. 2007, 31, 536-545. [CrossRef] [PubMed] 
43. Mulay, S.R.; Evan, A.; Anders, H.J. Molecular mechanisms of crystal-related kidney inflammation and injury. Implications for cholesterol embolism, crystalline nephropathies and kidney stone disease. Nephrol. Dial. Transplant. 2014, 29, 507-514. [CrossRef] [PubMed]

44. Gonzalez, A.P.; Juega, J.; Vazquez, C.; Hernandez-Gallego, A.; Lopez, D.; Canas, L.; Bancu, I.; Bonet, J.; Lauzurica, R. Late Onset of Cholesterol Embolism Leading to Graft Failure After Renal Transplantation: Report of Two Cases. Transplant. Proc. 2015, 47, 2361-2363. [CrossRef] [PubMed]

45. Scolari, F.; Tardanico, R.; Pola, A.; Mazzucchelli, C.; Maffeis, R.; Bonardelli, S.; Maiorca, P.; Movilli, E.; Sandrini, S. Cholesterol crystal embolic disease in renal allografts. J. Nephrol. 2003, 16, 139-143. [PubMed]

46. Herzog, A.L.; Wanner, C. Case Report: Atheroembolic renal disease in a 72-year-old patient through coronary intervention after myocardial infarction. Hemodial. Int. 2008, 12, 406-411. [CrossRef] [PubMed]

47. Donohue, K.G.; Saap, L.; Falanga, V. Cholesterol crystal embolization: An atherosclerotic disease with frequent and varied cutaneous manifestations. J. Eur. Acad. Dermatol. Venereol. 2003, 17, 504-511. [CrossRef] [PubMed]

48. Scolari, F.; Ravani, P.; Pola, A.; Guerini, S.; Zubani, R.; Movilli, E.; Savoldi, S.; Malberti, F.; Maiorca, R. Predictors of renal and patient outcomes in atheroembolic renal disease: A prospective study. J. Am. Soc. Nephrol. 2003, 14, 1584-1590. [CrossRef] [PubMed]

49. Granata, A.; Insalaco, M.; di Pietro, F.; di Rosa, S.; Romano, G.; Scuderi, R. Atheroembolism renal disease: Diagnosis and etiologic factors. Clin. Ter. 2012, 163, 313-322. [PubMed]

50. Cosio, F.G.; Zager, R.A.; Sharma, H.M. Atheroembolic renal disease causes hypocomplementaemia. Lancet 1985, 2, 118-121. [CrossRef]

51. Desai, M.; Ram, R.; Prayaga, A.; Dakshinamurty, K.V. Cholesterol crystal embolization (CCE): Improvement of renal function with high-dose corticosteroid treatment. Saudi J. Kidney Dis. Transpl. 2011, 22, 327-330. [PubMed]

52. Fabbian, F.; Catalano, C.; Lambertini, D.; Bordin, V.; di Landro, D. A possible role of corticosteroids in cholesterol crystal embolization. Nephron 1999, 83, 189-190. [CrossRef] [PubMed]

53. Stabellini, N.; Cerretani, D.; Russo, G.; Rizzioli, E.; Gilli, P. Renal atheroembolic disease: Evaluation of the efficacy of corticosteroid therapy. G. Ital. Nefrol. 2002, 19, 18-21. [PubMed]

54. Kronzon, I.; Tunick, P.A. Aortic atherosclerotic disease and stroke. Circulation 2006, 114, 63-75. [CrossRef] [PubMed]

55. Mann, S.J.; Sos, T.A. Treatment of atheroembolization with corticosteroids. Am. J. Hypertens. 2001, 14, 831-834. [CrossRef]

56. Nakayama, M.; Izumaru, K.; Nagata, M.; Ikeda, H.; Nishida, K.; Hasegawa, E.; Ohta, Y.; Tsuchihashi, T.; Urabe, $\mathrm{K}$. The effect of low-dose corticosteroids on short- and long-term renal outcome in patients with cholesterol crystal embolism. Ren. Fail. 2011, 33, 298-306. [CrossRef] [PubMed]

57. Abela, G.S.; Vedre, A.; Janoudi, A.; Huang, R.; Durga, S.; Tamhane, U. Effect of statins on cholesterol crystallization and atherosclerotic plaque stabilization. Am. J. Cardiol. 2011, 107, 1710-1717. [CrossRef] [PubMed]

58. Ishiyama, K.; Sato, T.; Taguma, Y. Low-Density Lipoprotein Apheresis Ameliorates Renal Prognosis of Cholesterol Crystal Embolism. Ther. Apheresis Dial. 2015; 19, 355-360.

59. Vogt, A. Hyperlipoproteinaemia(a)—Apheresis and emerging therapies. Clin. Res. Cardiol. Suppl. 2017, 12 (Suppl. S1), 12-17. [CrossRef] [PubMed]

60. Belenfant, X.; Meyrier, A.; Jacquot, C. Supportive treatment improves survival in multivisceral cholesterol crystal embolism. Am. J. Kidney Dis. 1999, 33, 840-850. [CrossRef]

61. Shames, M.L.; Rubin, B.G.; Sanchez, L.A.; Thompson, R.W.; Sicard, G.A. Treatment of embolizing arterial lesions with endoluminally placed stent grafts. Ann. Vasc. Surg. 2002, 16, 608-612. [CrossRef] [PubMed]

62. Theriault, J.; Agharazzi, M.; Dumont, M.; Pichette, V.; Ouimet, D.; Leblanc, M. Atheroembolic renal failure requiring dialysis: Potential for renal recovery? A review of 43 cases. Nephron Clin. Pract. 2003, 94, c11-c18. [CrossRef] [PubMed]

63. Jeyabalan, G.; Wallace, J.R.; Chaer, R.A.; Leers, S.A.; Marone, L.K.; Makaroun, M.S. Endovascular strategies for treatment of embolizing thoracoabdominal aortic lesions. J. Vasc. Surg. 2014, 59, 1256-1264. [CrossRef] [PubMed] 
64. Faria, B.; Vidinha, J.; Pego, C.; Garrido, J.; Lemos, S.; Lima, C.; Sorbo, G.; Gomes, E.L.; Carvalho, T.; Loureiro, P.; Sousa, T. Atheroembolic renal disease with rapid progression and fatal outcome. Clin. Exp. Nephrol. 2011, 15, 159-163. [CrossRef] [PubMed]

65. Dahlberg, P.J.; Frecentese, D.F.; Cogbill, T.H. Cholesterol embolism: Experience with 22 histologically proven cases. Surgery 1989, 105, 737-746. [PubMed]

66. Thadhani, R.I.; Camargo, C.A., Jr.; Xavier, R.J.; Fang, L.S.; Bazari, H. Atheroembolic renal failure after invasive procedures. Natural history based on 52 histologically proven cases. Medicine 1995, 74, 350-358. [CrossRef] [PubMed]

67. Frank, R.D. Cholesterol embolism syndrome: A rare, but severe complication in patients with atherosclerosis. Dtsch. Med. Wochenschr. 2012, 137, 1130-1134. [PubMed]

68. Machino-Ohtsuka, T.; Seo, Y.; Ishizu, T.; Sekiguchi, Y.; Sato, A.; Tada, H.; Watanabe, S.; Aonuma, K. Combined assessment of carotid vulnerable plaque, renal insufficiency, eosinophilia, and hs-CRP for predicting risky aortic plaque of cholesterol crystal embolism. Circ. J. 2010, 74, 51-58. [CrossRef] [PubMed]

69. Zuccala, A.; Zucchelli, P. A renal disease frequently found at postmortem, but rarely diagnosed in vivo. Nephrol. Dial. Transplant. 1997, 12, 1762-1767. [CrossRef] [PubMed]

70. Nasri, H.; Mubarak, M. Contrast induced nephropathy has to be differentiated from kidney injury due to atheroembolic disease. J. Renal. Inj. Prev. 2013, 2, 107-108. [PubMed]

(C) 2017 by the authors. Licensee MDPI, Basel, Switzerland. This article is an open access article distributed under the terms and conditions of the Creative Commons Attribution (CC BY) license (http://creativecommons.org/licenses/by/4.0/). 